Vittoratos: Yes it does. If the depth of the explosion is small, then the strength of the shock wave may be large enough to crack the ice, or even to eject some of it. In that case the present approach is not appropriate. For a cracked surface it is difficult to write an expression for the pressure on the ice surface caused by the incompressible expansion of the bubble. One expedient, if not correct, limit, is to assume that the ice behaves as a free surface; for a heavily damaged sheet this may not be a bad approximation. Venting of the bubble at an early stage will decrease the damage to the ice sheet. It should be noted that the consideration of the interaction of a shock wave with the ice presents considerable difficulties because of diffraction effects and possible cavitation at the ice-water interface.

\title{
AN ACOUSTIG RANGING SYSTEM TO MEASURE MOTION OF SEA ICE
}

\author{
By R. H. Goodman and R. C. Clark \\ (Innovative Ventures Ltd, Calgary, Alberta $\mathrm{T}_{2} \mathrm{E}_{2} \mathrm{~W}_{7}$, Canada)
}

Abstract. With the present increase of commercial activity in the Arctic Ocean, there is a growing need for advanced engineering techniques and instrumentation. This paper discusses the application, design and testing of an acoustic ranging system used to measure the motion of sea ice at potential ice-platform drilling locations in the Canadian Arctic.

\section{DISCUSSION}

W. F. WEEKS: Roughly how much would this system cost and how much lateral displacement of the ice can you tolerate before your system stops functioning?

R. Clark: The cost is about $\$ 20$ ooo with $\$ 2$ ooo of this being an irrecoverable cost of the pinger. The horizontal range of the system is $1 \cdot 5^{-2} \mathrm{~km}$.

K. R. Croasdale: Doesn't the horizontal range also depend on water depth?

Clark: Yes. The value decreases with decreased water depth. In the previous case, the value referred to depths of $300-400 \mathrm{~m}$.

W. St. Lawrence: What type of batteries are you using that operate at $-50^{\circ} \mathrm{C}$ ?

CLARK: We are using lead-acid batteries that have a concentrated acid and are designed for low discharge. These are very cost-effective and have operated successfully over four months with considerable capacity remaining.

St. Lawrence: Are you telemetering the data?

CLARK: Yes, development of satellite transmission of the data is underway at present and will be available for this winter's field season.

D. T. MELDRum: Your technique relies on the measurement of the small difference in arrival time of the pulse at the receivers to give the position of the ice. Changes in lateral position are inferred from changes in these small differences. However, vertical tilting of the ice mass could give rise to similar changes; and in fact the system will be much more sensitive to this than to lateral motion since path-length changes are effected more directly. Have you evidence whether vertical motion is involved? 
Clark: Vertical ice suction is small with respect to the water depth and thus does not noticeably influence the measurements. Vertical tilting over a short period would be partially considered by the averaging during the data-collection state, in this period 64 signals are averaged to give the single hourly reading. Tilting over a longer period would appear in the hourly readings taken. Problems associated with the movement of the ice are still being considered.

R. Frederking: Are you planning to carry out the development of this apparatus to the point where it can be used operationally in a drilling operation?

CLARK: Yes. At present the data is collected in a raw, unprocessed form on magnetic tape. Development is under way to use a mini-computer for on-site processing and real-time display.

S. F. Ackley: Have you attempted to correlate the ice-motion measurements with the measured meteorological and oceanographic parameters?

Clark: No, the data has only been obtained recently (July 1976) and it is currently under study.

Ackley: Acoustic releases may be useful for recovering the pingers.

Clark: This has been used on current meters installed in open water. However, with an ice cover, the problem is not to get the pinger to the surface, but to recover it from under the ice.

S. C. Colbeck: How much lateral ice motion can a floating drill-rig stand before it is no longer possible to re-enter the drill hole?

Clark: The "rule-of-thumb" accepted by the oil industry is $5 \%$ of the water depth. Beyond this limit, stresses are generated in the drill pipe and re-entry also becomes more difficult.

V. Schyтt : For how long does the ice-floe have to be stationary to permit the drilling of a hole?

GLARK: The length of time needed depends on the depth of the geological formation that is of interest and the problems encountered during the drilling. During 2-3 months, a hole of about $\mathrm{I}$ ooo $\mathrm{m}$ can be handled.

\title{
MATHEMATICAL SIMULATION OF THE PROGESS OF MOTION OF A SNOW AVALANGHE
}

\author{
By S. S. Grigoryan and A. V. Ostroumov
}

(Institut Mekhaniki, Moskovskiy Gosudarstvennyy Universitet im. M.V. Lomonosova, Michurinskiy Prospekt, Moscow V-234, U.S.S.R.)

Abstract. A "hydraulic" model of the motion of bed-type snow avalanches is developed, its qualitative particularities are discussed, and results of comparison of prediction and observations are presented. The proposed model allows calculation of the parameters of motion of snow avalanches possible for a given bed depending on the snow situation and other conditions. The characteristics concerned are the distribution of velocities averaged over the cross-section of the flow and the thickness of snow in an avalanche at every instant of its motion.

The class of avalanches considered is that in which a compact snow flow moves along a distinct avalanche bed consisting of an accumulation region, a bed, and an avalanche cone. It is proposed to model the avalanche bed with a certain inclined and curved channel of given 